\title{
Free will and psychiatric assessments of criminal responsibility: a parallel with informed consent
}

\author{
Gerben Meynen
}

Published online: 28 April 2010

(C) The Author(s) 2010. This article is published with open access at Springerlink.com

\begin{abstract}
In some criminal cases a forensic psychiatrist is asked to make an assessment of the state of mind of the defendant at the time of the legally relevant act. A considerable number of people seem to hold that the basis for this assessment is that free will is required for legal responsibility, and that mental disorders can compromise free will. In fact, because of the alleged relationship between the forensic assessment and free will, researchers in forensic psychiatry also consider the complicated metaphysical discussions on free will relevant to the assessment. At the same time, there is concern about the lack of advancement with respect to clarifying the nature of the forensic assessment. In this paper I argue that, even if free will is considered relevant, there may be no need for forensic researchers to engage into metaphysical discussions on free will in order to make significant progress. I will do so, drawing a parallel between the assessment of criminal responsibility on the one hand, and the medical practice of obtaining informed consent on the other. I argue that also with respect to informed consent, free will is considered relevant, or even crucial. This is the parallel. Yet, researchers on informed consent have not entered into metaphysical debates on free will. Meanwhile, research on informed consent has made significant progress. Based on the parallel with respect to free will, and the differences with respect to research, I conclude that researchers on forensic assessment may not have to engage into metaphysical discussions on free will in order to advance our understanding of this psychiatric practice.
\end{abstract}

\section{G. Meynen ( $\square)$}

Faculty of Philosophy, EMGO Institute VU Medical Center,

VU University Amsterdam, De Boelelaan 1105,

1081 Amsterdam, The Netherlands

e-mail: g.meynen@ph.vu.nl
Keywords Free will - Criminal responsibility · Informed consent $\cdot$ Forensic psychiatry $\cdot$ Law

\section{Introduction}

In some criminal cases a forensic psychiatrist is asked to make an assessment about the state of mind of the defendant at the time of the legally relevant act. More precisely, the forensic expert is asked to relate the state of mind to the legally relevant act. ${ }^{1}$ Based on the assessment, a statement has to be made on the legal accountability of the defendant. ${ }^{2}$ The results of such a forensic assessment may have profound impact on the eventual verdict. Apparently, we are interested in the state of mind of the defendant in terms of a mental disorder, and we turn out to be willing to attach major legal consequences to the outcome of a forensic psychiatric assessment.

Perhaps surprisingly, the conceptual basis for this psychiatric assessment is unclear. We do not know what it is exactly, that a mental disorder 'does' to render a person not responsible for a specific act. Meanwhile, several rules for the 'insanity defense' have been formulated, the most influential being the M'Naghten Rule. ${ }^{3}$ The different rules

\footnotetext{
${ }_{1}$ In this paper I approach the assessment as a psychiatric practice, but certainly also psychologists are involved in these assessments.

${ }^{2}$ Some forensic experts are reluctant to make a specific statement on what they consider to be the 'ultimate question' of legal accountability. It has been argued that psychiatrists should not make the inference that the person is actually responsible for the legally relevant act, or that this statement should be phrased explicitly as an opinion (Gutheil 2005). The 'ultimate question' should be answered, then, by judge or jury. I do not intend to take a specific position in these matters. I will mainly refer to 'criminal responsibility' because it is a term often attached to the type of assessments discussed in this paper.

${ }^{3}$ See Elliott 1996 for an overview of and a reflection on these rules and the insanity defense.
} 
all have their advantages and shortcomings. None of them grasps our intuitions concerning the 'insanity defense' to full satisfaction (Elliott 1996).

Yet, a considerable number of people seem to hold that the basis for the forensic assessment is that free will is required for legal responsibility, and that mental disorders can compromise free will. As Reich (2005) puts it: "The law recognizes that insanity compromises free will, and classifies someone without free will as legally not responsible for his or her actions." ${ }^{4}$ The forensic psychiatrist's task, then, is to assess whether the legally relevant act was performed 'freely', or that, alternatively, a mental disorder decisively influenced the process leading up to the act. The fact that free will is considered central also explains why psychiatrists in their actual testimonies before the court sometimes use phrases like "the defendant is not accountable for the act because she did not perform it freely, but due to a paranoid delusion" (Morse 2007). In fact, because of the alleged relationship between the forensic assessment and free will, researchers on forensic assessment have considered the complicated metaphysical discussions on free will relevant to the assessment (Stone 2008; Luthe and Rösler 2004; see Morse 2007 for a critique).

In this paper I will develop an argument showing that researchers on forensic assessment may not have to engage in metaphysical discussions on free will, even if free will is considered relevant to forensic assessment. I will do so, drawing a parallel between the assessment of criminal responsibility on the one hand, and the medical practice of obtaining informed consent on the other. I argue that also with respect to informed consent, free will is considered relevant. ${ }^{5}$ Yet, researchers on informed consent, unlike researchers on criminal responsibility, have not engaged in metaphysical debates on free will. ${ }^{6}$ Meanwhile, significant progress has been achieved in research on informed consent (see "A parallel: informed consent"). I argue that research on informed consent could provide a helpful model for research on forensic assessment.

The structure of the paper is as follows. In the next section I will briefly present the philosophical debate on free will. In section "Forensic assessment and free will", I will discuss the impact of the philosophical worries on forensic psychiatry. In section "A parallel: informed con-

\footnotetext{
${ }^{4}$ See also Sect. 3.

5 See Sect. 4 for examples.

${ }^{6}$ It is hard to prove the absence of something, but it is safe to say that while the metaphysical issues surrounding free will constitute a well known (notorious) topic with respect to criminal responsibility in forensic psychiatry (see also Sect. 3), this is not the case with respect to informed consent.
}

sent", a parallel will be drawn with (research on) informed consent. In sections "Potential of the parallel" and "Empirical ethics" I will explore the potential of this parallel for forensic psychiatry.

\section{The metaphysics of free will}

In this section I will briefly present the complicated philosophical issues concerning free will. ${ }^{7}$ The purpose of this section is to show that, indeed, there is a serious philosophical free will problem.

To start with, there is no consensus among philosophers on how to define free will. Walter (2001) distinguishes three main aspects or components of free will in the present philosophical debate. The first component is, that to be free one must be able to do otherwise. Second, to be free means to act or choose for an understandable reason. And, third, freedom requires that one is the originator of one's actions. A large part of the current philosophical discussion on free will is concerned with the question to what extent these three aspects really are essential to the concept of free will (Walter 2001) For instance, many philosophers currently believe that having alternative possibilities is in fact not a requirement for free will or moral responsibility (Widerker and McKenna 2003; Kane 2002). In this paper I will not take a specific position on how to understand free will. The philosophical unclarity about its definition is a fact, and the paper is about dealing with the unclarity in forensic psychiatry, not trying to solve it philosophically (see also Meynen 2009a). ${ }^{8}$

Although there are profound problems attached to defining free will, another problem appears to be even more pressing. For philosophers have not been able to figure out whether or not free will is compatible with a deterministic world (Kane 2002; Searle 2007). Determinism is, briefly,

\footnotetext{
${ }^{7}$ In this paper I will refer to the philosophy of free will mostly as 'metaphysics'. Meanwhile, free will is often approached from the perspective of responsibility (see, e.g., Pereboom 2001; Kane 2002). More precisely, while the compatibility between free will and determinism might be considered a strictly metaphysical issue, establishing the requirements for moral responsibility can be considered a 'metaethical' or 'ethical' concern. In practice, however, in the discussion on free will, metaphysics and (meta)ethics have become intertwined to a large extent (see, e.g., The Oxford Handbook of Free will by Kane 2002; Pereboom 2001). For instance, the issue whether we can be held responsible for a choice while we did not have alternative possibilities, can be perceived as a (meta)ethical question, but it can also be crucial in the metaphysical debate on the compatibility between free will and determinism.

${ }^{8}$ In philosophical discussions on free will, free will is often used as synonymous with 'freedom', and sometimes with acting 'freely' (Kane 2002). In line with this use of the words, I will consider 'freedom' as referring to 'free will', both in philosophical literature and in the literature on criminal responsibility and informed consent.
} 
the thesis that whatever happens is inevitable or necessary, either by fate, or by the will of God, or by the laws of nature (Kane 1998, 2002). Some believe that the everyday world in which we live is governed by deterministic natural laws (Kane 1998). Philosophers have not been able to establish whether in such a world free will can actually exist. And the discussion on the possible existence of free will is not only waged among philosophers, also (neuro)scientists are participating in the debate (Kawohl and Habermeyer 2007; Walter 2001; Kane 2002; Gazzaniga 2005). In addition, we have to note that not only determinism, but also indeterminism appears to be problematic for free will. For what room would be left for free will, if everything happened by chance? (Kane 2002) But this issue, somehow, is less prominent in the philosophical debate (Kane 2002).

In general, there are three main philosophical positions on the compatibility of freedom and determinism: compatibilism, hard determinism and libertarianism (Kane 2002). Briefly, hard determinists not only hold that free will and determinism are incompatible, they also consider determinism true, and, therefore, they deny free will. All events relate to each other like billiard ball collisions. Libertarians have the opposite view. Although they agree that freedom and determinism are incompatible, they affirm free will, and, therefore, consider determinism false. The deterministic chain of events is broken, at least at some points in time, they say. Compatibilism, the most popular position, holds that even in a deterministic world there can still be significant freedom-free will "worth wanting", as Dennett puts it (Dennett 2003). These three philosophical positions have basically existed for centuries. To the philosopher Searle (2007) the persistence of the problem of free will seems 'something of a scandal' (Searle 2007), because no substantial progress on this problem has been made. And, on Searles account (2007), no solution is in sight: "The problem of free will is unusual among contemporary philosophical issues in that we are nowhere remotely near having a solution" (see also Meynen 2009a).

As it appears, psychiatrists cannot expect philosophers to provide them with a solution anytime soon.

\section{Forensic assessment and free will}

Given this state of affairs it may be understandable that people feel uncomfortable when forensic assessment is understood in terms of 'free will'. For instance, when Stone in a paper on forensic psychiatry says about the issue of "determinism v. free will" that it is "relevant to every question of volition and responsibility" (Stone 2008). Forensic practitioners also may feel uncomfortable when Kawohl and Habermeyer (2007) write that "the psychiatrist as an expert witness is forced to find a practical way to deal with the existence of the critical term free will". ${ }^{9}$ Since philosophers do not agree on what free will is, and whether it exists, this engagement in philosophical discussions could even undermine the reliability of the forensic assessment. Yet, not all forensic experts and theorists are convinced that free will is central. For instance, Morse (2007) has argued, aware of the metaphysical complexities surrounding free will, that it is confused to consider free will vital or even relevant to forensic assessment. For no legal doctrine or legal document (in the USA) explicitly mentions that free will is implicated. And, in order to avoid confusion, the best thing forensic psychiatrists can do is to stop thinking about free will. ${ }^{10}$ It is safe to say that at this moment there is no consensus on the relevance of (the metaphysics of) free will to the forensic assessment. We could, of course, try to device a conclusive argument either showing its relevance or its irrelevance. Yet, this is not my approach in this paper. I will propose a way to deal with 'free will' in forensic psychiatry in the absence of such a conclusive argument or consensus. ${ }^{11}$

In the remainder of the paper I will try to show that even if free will is considered relevant, forensic experts and researchers do not necessarily have to feel obliged to engage in metaphysical discussions in order to clarify the nature of the assessment. In the next section I will link assessments of criminal responsibility to the practice of obtaining informed consent. Via this link, I will arrive at a suggestion how to deal with the issue of 'free will' in forensic psychiatry.

\section{A parallel: informed consent}

The attention paid by forensic theorists to philosophical arguments on free will might have seemed 'logical' because of the widely shared intuition that assessments of

\footnotetext{
${ }^{9}$ Cf. Barendregt et al. 2008, Dressing 2007, and Alper 1998. See also Van Marle (2000), explaning the practice of forensic assessments in the Netherlands: "Undiminished responsibility means that the person concerned had complete access to his or her free will at the time of the crime with which he or she is charged and could therefore have chosen not to do it. Irresponsibility means that the person concerned had no free will at all with which to choose at the time of the crime with which he or she is charged. Important here is determining the moment when aspects of the disorder become manifest in the situation ("the scene of the crime") that will eventually lead to the perpetration. The earlier they play a role, the more inevitable will be the (disastrous) sequence of events, and the stronger will be the eventual limitation of free will."

${ }^{10}$ Meynen (2009a) has argued that Morse's argument is not conclusive.

${ }^{11}$ I do not claim that free will is required for criminal responsibility, or that it is by compromising free will that mental disorder can suspend criminal responsibility.
} 
criminal responsibility have to do with 'free will'. Yet, from another angle it may seem remarkable that metaphysical concerns have so deeply penetrated the discussions on forensic assessments. In fact, freedom is not only considered to be involved in forensic assessment of legal accountability, but also in another medical practice: the 'everyday' medical practice of obtaining informed consent to treatment. Still, although also this practice is considered to be related to free will (see below), attempts to elucidate this practice have not led to engagements into the slippery metaphysics of free will.

I will give a few examples of 'free will' or 'free choice' in literature on informed consent. As Simon (2005) puts it, rational decision making about treatment occurs when a patient's consent to treatment "reflects" that patient's "freedom of choice". According to Welie and Welie (2001), patients can only be considered competent and responsible for the decisions on treatment they make, if they were "free and able to reach a different decision". Paterick et al. (2008) state that, "to give valid informed consent, the patient must be competent and the patient's actions must be voluntary. Voluntary means "of free mind and free will." And Pinals and Appelbaum (2002, p. 479) write that: "Generally, informed consent, whether to research or treatment, is broken down into three parts: voluntariness, disclosure, and competence. Voluntariness implies that research subjects must be acting of their own free will when they agree to participate in research." Finally, Roberts (2002) emphasizes the importance of voluntarism, which she defines as "ideally encompassing the individual's ability to act in accordance with one's authentic sense of what is good, right, and best in light of one's situation, values, and prior history. Voluntarism involves the capacity to make this choice freely and in the absence of coercion." In other words, notions of "free will" and "free choice" are considered tightly connected to (the concept of) informed consent. ${ }^{12}$

Since the concept of freedom is present in conceptual reflections on obtaining informed consent, also this medical practice is, in principle, not immune to philosophical discussions on free will. For instance, we could ask ourselves: could a patient make a 'free' decision about treatmentand therefore give genuine informed consent-in a deterministic world? This question has a comparable form as the

\footnotetext{
12 Other examples can be found in Rosenfeld (2002), Palmer and Kaufman (2003), Thomasmaa (2000), and Yank et al. (2002). Interestingly, Elliott (1991) even proposed to conceive of competence to consent to treatment in terms of accountability. He argued that, in essence, what we want from patients when they make their decisions on medical treatment, is that they can be justifiably be held accountable for these decisions. So, his analysis brings him to exactly the same concept that is considered central in forensic assessment of criminal responsibility - the very concept that brought free will deep into forensic theorizing.
}

question: can we ascribe accountability to a person in a deterministic world? Yet, this type of questions has not really troubled researchers on informed consent.

I do not claim that all the senses in which 'free will' and 'freedom' or 'free choice' feature in the debates on assessments criminal responsibility and informed consent are identical. This would require detailed arguments. Yet, it seems clear that matters of 'freedom', 'free will', and 'free action/choice' are present in literature on both practices. Meanwhile, the literature on informed consent has, basically, not engaged into metaphysical discussions on free will. This shows that, apparently, even if matters of freedom are considered relevant, one is still free to decide (not) to engage into metaphysical discussions.

In principle, it could be that the metaphysics of free will have not penetrated discussions on competence because nobody is interested in the conceptual background of this assessment. ${ }^{13}$ But this is, certainly, not the case. Many efforts have been undertaken to achieve conceptual and operational clarification with respect to informed consent (Appelbaum 2007; Welie 2001). As a result of these efforts, it has been possible to propose specific criteria, like the criteria for competence to consent to treatment (Appelbaum 2007). In addition, scales have been developed to assist physicians in examining a person's competence to consent to treatment, especially the MacArthur (MacCAT) scale (Grisso et al. 1997). Surely, there remains unclarity about the criteria for competence, and there is at present no 'gold standard' that tells a physician what competence is (Appelbaum 2007; Spike 2008). Yet, using the criteria and using the MacArthur scale valuable clinical data have been obtained (see, e.g., Owen 2008). Although the MacCAT scale may be the most widely used in research on informed consent (Jeste et al. 2006), it is not known exactly to what extent in everyday clinical practice this tool or the Appelbaum (2007) criteria are being used. In this respect it might also be noteworthy that, as Welie observed (2008, p. 87) in an empirical study on competence in a relevant health care setting, "the issue of patient decision-making competence was not a topic of debate or discussion at all among the observed health care professionals."

Meanwhile, with respect to the forensic assessment it has turned out to be difficult to achieve such conceptual and practical progress, and there are concerns about the lack of clarity of the assessment (Murrie and Warren 2005; Barendregt et al. 2008; Rogers and Shuman 2005; Henderson 2005). In part, forensic efforts for conceptual elucidation have been absorbed by discussions on (the

\footnotetext{
${ }^{13}$ I will not explore why it is that this has not happened.
} 
relevance of philosophical worries on) free will (Morse 2007; Felthous 2008). ${ }^{14}$

In conclusion, there is a significant parallel between the two medical practices: both are considered to be related to notions of 'freedom', 'free will', or 'choosing or acting freely'. ${ }^{15}$ Meanwhile, there is a significant difference with respect to the extent to which research on these practices has been absorbed by metaphysical concerns about free will (and determinism). In addition, there is a difference with respect to the level of conceptual and practical elucidation that has been achieved in both practices. ${ }^{16}$

In the next section, I will explore what could be considered to be the 'potential' of the parallel.

\section{Potential of the parallel}

As it appears, in research on informed consent it has been possible to work effectively on conceptual and operational clarification, without either denying the relevance of freedom to informed consent, or adopting an explicit metaphysical stance on the compatibility of freedom and determinism. ${ }^{17}$ If we translate this to the forensic assessment, we could argue that even if freedom is considered to be involved in the forensic assessment, (the metaphysical problem of) freedom does not have to be approached 'head-on' in order to achieve certain conceptual and operational elucidation of this assessment. In other words, forensic psychiatry may not need to adopt a specific stance on the metaphysical issue of free will and its relevance to the assessment. Surely, solving the metaphysical problems could be of (great) help, but as it appears, this could take a while. Based on the parallel, I am pointing to the possibility that some relevant progress can be achieved with respect to the psychiatric assessment, even if 'free will' is not (philosophically) addressed. ${ }^{18}$ In my view, this practical argument could be helpful in deciding how to deal with the issue of free will in forensic research.

Certainly, there are also relevant differences between forensic assessment and assessments of competence (for an exploration of differences and similarities between these assessments see Meynen 2009b). These are for a large part related to the fact that while forensic assessments are

\footnotetext{
$\overline{14}$ I certainly do not mean to dismiss the efforts that have been undertaken (see Rogers and Shuman 2005).

15 Not by everyone, but still by a considerable number of researchers (I am not claiming that they are right or that they are wrong).

16 This will, of course, also have to do with the fact that many more people are involved in research on informed consent.

17 See also Grubin 2008.

18 I am not claiming that full understanding can be achieved without philosophical considerations.
}

performed in a juridical environment and related to an offence, assessments of competence are performed in a medical environment related to choosing a treatment option. Therefore, also the consequences of the assessment may differ: punishment (in case of forensic assessment) and treatment (in case of assessments of competence). In addition, due to the nature of forensic assessment, in which the court has to be informed, in forensic assessment there is not the kind of confidentiality which exists in the normal doctor patient relationship (Gutheil 2005). However, both are medical assessments_-in which psychiatrists are often considered experts - on capacities of a person which are considered to be related to 'free will', 'free action' and 'free choice'. This is the similarity or parallel I want to bring forward in this paper.

Based on these considerations, I argue, forensic researchers could justify avoiding the philosophical issue of free will. This is not because the matter would be irrelevant, or because the metaphysical problems would have been solved, but because research on a medical practice which is considered to be related to free will, apparently does not have to deal with free will head-on in order to achieve relevant progress. My suggestion does not require that we consider free will irrelevant in the forensic assessment. Yet, we do not have to feel forced into a possibly fruitless metaphysical discussion on free will in order to achieve some clarification of the forensic assessment.

Still, I do feel that there is something more to be learnt from research on informed consent. ${ }^{19}$ For I have approached this kind of research mainly in a negative way: looking at what it has not been doing (getting into metaphysical debates on free will). But what type of research has been performed?

\section{Empirical ethics}

Much of the research on informed consent can be characterized by an 'empirical ethics approach' (Candilis et al. 2008). Perhaps, this type of research, which I will briefly discuss in this section, could also be helpful to forensic psychiatry. $^{20}$

\footnotetext{
${ }^{19}$ On the other hand, one could argue that research on informed consent has ignored the philosophical views of free will on. But this is not the point I make in this paper.

${ }^{20}$ See also Meynen 2009b and c. For discussions on the practice and conceptual underpinnings of empirical ethics in psychiatry, see, e.g., Eastman and Starling 2006, Widdershoven et al. 2009, McMillan and Hope 2008. A central issue with respect to empirical ethics in general is the question: How can empirical data give rise to normative conclusions?, which comes down to the "is-ought gap", as discussed by, e.g., Van der Scheer and Widdershoven (2004).
} 
Empirical ethics may take many forms (Eastman and Starling 2006; Widdershoven et al. 2008). In general, it aims, alongside ethical theorizing, to obtain specific qualitative empirical data. It can do so via different methods: observations, interviews questionnaires, etc. (Widdershoven et al 2008). Empirical ethics has been a helpful approach to many complicated, normative medical issues, like questions about end-of life decisions, and also competence and informed consent (Widdershoven et al. 2008; Eastman and Starling 2006). In my view, the assessment of criminal responsibility has comparable features: being complicated, normative, and medical in nature. ${ }^{21}$

One approach in empirical medical ethics, so called stakeholder dialogue, tries to unite different stakeholders around a conceptual or normative issue. In this type of study, as Widdershoven et al. (2009) point out, it is essential that "data are gathered, not about participants in practice, but together with practitioners (...)." Via such a dialogue, in which several stakeholder groups participate around a (complicated) normative topic, mutual understanding between different stakeholder groups can also be enhanced (Widdershoven et al. 2009). Especially because of the profoundly interdisciplinary terrain of forensic psychiatry, it is important that the method used can lead to an outcome that is likely to be both relevant and acceptable to the different parties involved. ${ }^{22}$ This could be a reason to consider stakeholder dialogue. Stakeholders with respect to assessments of criminal responsibility are, among others, judges, lawyers and psychiatrists. An important characteristic of empirical (medical) ethics in general is that it is familiar with research at the interface of medicine and law (Eastman and Starling 2006).

The question can be raised whether, given certain similarities between the assessments of competence and criminal responsibility (see also Meynen 2009b), there could be a direct translation of the criteria for informed consent to the context of forensic assessments. I do not want to exclude this possibility, yet, for instance concerning the Appelbaum criteria, each of them should be considered carefully with respect to the (practical) relevance and helpfulness in forensic settings. I rather suggest to consider the methods of empirical ethics in general as potentially helpful, than to propose a direct translation of, e.g., the MacCAT (see also Hondius 2009).

\footnotetext{
${ }^{21}$ The topic in fact deserves a more elaborate argument, but within the framework of this paper I will restrict myself to some more general remarks.

22 See Widdershoven et al. (2009) for a discussion on stakeholder dialogue, also with respect to the integration of empirical data, and the role of the ethicist in this process (also as related to so called responsive evaluation).
}

Recent research that, perhaps, could also be valuable within the framework of 'empirical ethics', is the approach by Barendregt et al. (2008). ${ }^{23}$ They studied empirically the factors on which forensic experts actually base their judgements concerning criminal responsibility. They motivate their approach saying that many papers addressing criminal responsibility focus on what "forensic experts ought to include in evaluating a defendant's criminal responsibility", but that in spite of these papers there is "hardly any consensus on what constitutes grounds for (diminished) responsibility". Barendregt et al. (2008) found that experts' judgements were not only based on the presence or absence of mental disorders, but also, e.g., on cultural and crime related characteristics, like the weapon used, or whether the act was committed alone or with others. Also from this type of research indications may be obtained for further elucidation of forensic assessment. Meanwhile, such research should not result in direct consequences for forensic assessment. It could rather deliver relevant new input data for the debate/dialogue among stakeholders about what it is that forensic assessment has to focus on. Still, surely, the factors that actually play a role in the assessment are not necessarily the factors that should play a role in the assessment. ${ }^{24}$ Yet, my proposal is not meant to eliminate all possible (conceptual) problems, but to argue for using an approach to clarifying the forensic assessment that has been effective in research on informed consent. This is an argument, then, derived from practical observation, namely that an empirical ethics approach is considered to have delivered relevant results with respect to informed consent (Candilis et al. 2008), rather than an argument derived from a conceptual justification of empirical ethics. Based on this observation, I suggest that empirical ethics may be a candidate for dealing with a fundamentally interdisciplinary issue (law, medicine) like forensic assessment.

In this paper, I do not intend to bring forward that engaging into philosophical reflections on free will is pointless with respect to forensic assessments. Yet, the complexities of certain philosophical issues could result in some sort of stalemate. We should try to avoid that efforts to elucidate the nature of the forensic assessment get stuck in the metaphysics of free will. Forensic researchers should feel free (not) to engage in philosophical debates, as long as that seems to be fruitful (Meynen 2009a).

\footnotetext{
${ }^{23}$ See also Meynen 2009c. Meanwhile, the research itself is not an 'empirical ethics approach'.

${ }^{24}$ See also Van der Scheer and Widdershoven (2004). The question might even arise whether empirical research could either directly or indirectly tell us more about the metaphysics of 'free will', in other words, whether 'empirical metaphysics' is possible, but addressing this question lies outside the scope of this paper.
} 


\section{Conclusion}

Forensic psychiatric assessment is not the only medical practice in which free will has been considered to be central. I argued that there is a parallel with the practice of obtaining informed consent. For also with respect to informed consent issues of 'free will' and 'free choice' are considered relevant or even central. Yet, there is a significant difference as well: researchers on informed consent have not engaged in metaphysical discussions on free will. Meanwhile, research on informed consent shows that relevant conceptual and operational clarification can be achieved, even if one does not engage in these debates. In fact, in research on informed consent, neither the involvement of free will has been denied, nor, for instance, the compatibility problem addressed. I suggest that, in this respect, research on informed consent could provide a helpful model for research on forensic assessment. In my view, especially given the persistent unclarity in forensic psychiatry, it is important to have a model for further research that is both feasible and potentially effective. More specifically, empirical ethics, as used in research on informed consent, might be a candidate approach to studying the assessment of legal accountability. Especially its interdisciplinary nature and its familiarity with the interface of medicine and the law seem to be valuable characteristics.

Acknowledgments This work is supported by NWO-VENI research-grant no. 275-20-016.

Open Access This article is distributed under the terms of the Creative Commons Attribution Noncommercial License which permits any noncommercial use, distribution, and reproduction in any medium, provided the original author(s) and source are credited.

\section{References}

Alper, J.S. 1998. Genes, free will, and criminal responsibility. Social Science and Medicine 46(12): 1599-1611.

Appelbaum, P.S. 2007. Assessment of patients' competence to consent to treatment. New England Journal of Medicine 357: $1834-1840$.

Barendregt, M., E. Muller, H. Nijman, and E. de Beurs. 2008. Factors associated with experts' opinions regarding criminal responsibility in The Netherlands. Behavioral Sciences \& The Law 26(5): 619-631.

Candilis, P.J., K.E. Fletcher, C.M. Geppert, C.W. Lidz, and P.S. Appelbaum. 2008. A direct comparison of research decisionmaking capacity: Schizophrenia/schizoaffective, medically ill, and non-ill subjects. Schizophrenia Research 99(1-3): 350-358.

Dennett, D.C. 2003. Freedom evolves. London: Penguin.

Dressing, H., H.J. Salize, and H. Gordon. 2007. Legal frameworks and key concepts regulating diversion and treatment of mentally disordered offenders in European Union member states. European Psychiatry 22: e427-e432.
Eastman, N., and B. Starling. 2006. Mental disorder ethics: Theory and empirical investigation. Journal of Medical Ethics 32: 94 99.

Elliott, C. 1991. Competence as accountability. Journal of Clinical Ethics 2: 167-171.

Elliott, C. 1996. The rules of insanity. Moral responsibility and the mentally ill offender. Albany: State University of New York.

Felthous, A.R. 2008. The will: From metaphysical freedom to normative functionalism. The Journal of the America Academy of Psychiatry and the Law 36: 16-24.

Gazzaniga, M.S. 2005. The ethical brain. New York: Dana.

Grisso, T., P.S. Applebaum, and C. Hill-Fotouhi. 1997. TheMacCATT: A clinical tool to assess patients' capacities tomake treatment decisions. Psychiatric Services 48: 1415-1419.

Grubin, D. 2008. Commentary: Mapping a changing landscape in the ethics of forensic psychiatry. The Journal of the American Academy of Psychiatry and the Law 36(2): 185-190.

Gutheil, T.G. 2005. Ethics and forensic psychiatry. In Psychiatric ethics, ed. S. Bloch, P. Chodoff, and S.A. Green, 345-362. Oxford: Oxford University Press.

Henderson, S. 2005. The neglect of volition. British Journal of Psychiatry 186: 273-274.

Hondius, A. 2009. Free will not to be neglected in forensic psychiatry (in Dutch). Tijdschrift voor Psychiatrie 51(12): 883-885.

Jeste, D.V., C.A. Depp, and B.W. Palmer. 2006. Magnitude of impairment in decisional capacity in people with schizophrenia compared to normal subjects: An overview. Schizophrenia Bulletin 32: 121-128.

Kane, R. 1998. The significance of free will. Oxford: Oxford University Press.

Kane, R. 2002. The oxford handbook of free will. Oxford: Oxford University Press.

Kawohl, W., and E. Habermeyer. 2007. Free will: Reconciling German civil law with Libet's neurophysiological studies on the readiness potential. Behavioral Sciences and the Law 25: 309-320.

Luthe, R., and M. Rösler. 2004. Freedom of will, freedom of action and psychiatry: Concerning the relationship of empirical to intelligible character and so-called freedom of choice in the view of forensic psychiatry. In Philosophy and psychiatry, ed. T. Schramme, and J. Thome, 295-308. Berlin: De Gruyter.

McMillan, J., and T. Hope. 2008. The possibility of empirical psychiatric ethics. In Empirical ethics in psychiatry, ed. G. Widdershoven, T. Hope, J. McMillan, and L. Van der Schee, 922. Oxford: Oxford University Press.

Meynen, G. 2009a. Should or should not forensic psychiatrists think about free will? Medicine, Health Care and Philosophy 12: 203212.

Meynen, G. 2009b. Exploring the similarities and differences between medical assessments of competence and criminal responsibility. Medicine, Health Care and Philosophy 12: 443-451.

Meynen, G. 2009c. Free will in forensic psychiatry (in Dutch). Dutch Journal of Psychiatry 51(12): 873-881.

Morse, S.J. 2007. The non-problem of free will in forensic psychiatry and psychology. Behavioral Sciences \& the Law 25: 203-220.

Murrie, D.C., and J.I. Warren. 2005. Clinician variation in rates of legal sanity opinions: Implications for self-monitoring. Professional Psychology: Research and Practice 36(5): 519-524.

Owen, G., Richardson, G., and David, A.S. 2008. Mental capacity to make decisions on treatment in people admitted to psychiatric hospitals: Cross sectional study. British Medical Journal. doi: 10.1136/bmj.39580.546597.BE.

Palmer, N., and M. Kaufman. 2003. The ethics of informed consent. Journal of Ethnic And Cultural Diversity in Social Work 12(1): 1-26.

Paterick, T.J., G.V. Carson, M.C. Allen, and T.E. Paterick. 2008. Medical informed consent: General considerations for physicians. Mayo Clinic Proceedings 83(3): 313-319. 
Pereboom, D. 2001. Living without free will. Cambridge: Cambridge University Press.

Pinals, D.A., and Appelbaum, P.S. 2002. Ethical aspects of neuropsychiatric research with human subjects. In: Neuropsychopharmacology: The Fifth Generation of Progress, ed. Kenneth L. Davis, Dennis Charney, Joseph T. Coyle, and Charles Nemeroff. USA: American College of Neuropsychopharmacology.

Reich, W. 2005. Psychiatric diagnosis as an ethical problem. In Psychiatric ethics, 3rd ed, ed. S. Bloch, P. Chodoff, and S. Green. Oxford: Oxford University Press.

Roberts, L.W. 2002. Informed consent and the capacity for voluntarism. American Journal of Psychiatry 159: 705-712.

Rogers, R., and D.W. Shuman. 2005. Fundamentals of forensic practice: Mental health and criminal law. New York: Springer.

Rosenfeld, B. 2002. The psychology of competence and informed consent: Understanding decision-making with regard to clinical research. Fordham Urban Law Journal 30(1): 173-185.

Searle, J.R. 2007. Freedom \& neurobiology. Reflections on free will, language, and political power. New York: Columbia University Press.

Simon, R.I. 2005. Ethics and forensic psychiatry. In Sadock's comprehensive textbook of psychiatry, 8th ed, ed. B.J. Sadock, and V.A. Sadock. Philadelphia: Lippincott Williams \& Wilkins.

Spike, J.P. 2008. Patients' competence to consent to treatment (Comment on Appelbaum 2007). New England Journal of Medicine 358(6): 644.

Stone, A.R. 2008. The ethical boundaries of forensic psychiatry: A view from the ivory tower. The Journal of the American Academy of Psychiatry and the Law 36(2): 167-174.
Thomasmaa, D.C. 2000. Model of community substituted consent for research on the vulnerable, p. 52. Medicine, Health Care and Philosophy 3: 47-57.

Van der Scheer, L., and G. Widdershoven. 2004. Integrated empirical ethics: Loss of normativity? Medicine, Health Care and Philosophy 7: 71-79.

Van Marle, H. 2000. Forensic psychiatric services in the Netherlands. International Journal of Law and Psychiatry 23(5-6): 515-531.

Walter, H. 2001. Neurophilosophy of free will. From libertarian illusions to a concept of natural autonomy. Cambridge: MIT.

Welie, S.P.K. 2001. Criteria for patient decision making (in)competence: A review of and commentary on some empirical approaches. Medicine, Health Care and Philosophy 4: 139-151.

Welie, J.V.M., and S.P.K. Welie. 2001. Patient decision making competence: Outlines of a conceptual analysis. Medicine, Health Care and Philosophy 4: 127-138.

Welie, S.P.K. 2008. Criteria for assessment of patient competence. A conceptual analysis from the legal, psychological and ethical perspectives. Davenport, Iowa (USA): Fidlar Doubleday Inc.

Widdershoven, G., T. Hope, J. McMillan, and L. Van der Scheer. 2008. Empirical ethics in psychiatry. Oxford: Oxford University Press.

Widdershoven, G., T. Abma, and B. Molewijk. 2009. Empirical ethics as dilogical practice. Bioethics 23(4): 236-248.

Widerker, D., and M. McKenna. 2003. Moral responsibility and alternative possibilities: Essays on the importance of alternative possibilities. Aldershot: Ashgate.

Yank, V., and D. Rennie. 2002. Reporting of informed consent and ethics committee approval in clinical trials. JAMA 287(21): 2835. 